\title{
Comparison of hemodynamic effect between the spinal anesthesia and saddle block during transurethral resection of the prostate
}

By

\author{
Dr. Farooq Taher Abdulqader ${ }^{* 1}$; Dr. Ali Abd-Alhameed Mohammed ${ }^{* 2}$ \\ ${ }^{* 1}$ M.B.Ch. B/ F.I.B.M.S. , A \&ICU/Ibn Al-Bitar specialized center for cardiac surgery; ${ }^{* 2}$ Consultant \\ Anesthetist/M.B.Ch. B /D. A/F.I.B.M.S /F.A.C.M.S A\&IC
}

Abstract

Background: The best technique for transurethral resection of prostate (TURP) is regional anesthesia. The hypotension is the major complication following spinal anesthesia. The hemodynamic changes is less with saddle block than spinal block. Aim and Objective: To compare hemodynamic effect between the spinal block and saddle block in TURP. Patients and methods: 50 patients between 50-70 years old ASA I II prepared for TURP, divided randomly in two groups $25 \mathrm{pt}$. in each group. Group A received spinal $10 \mathrm{mg}$ of hyperbaric bupivacaine ( $2 \mathrm{ml}$ of $0.5 \%$ ), were group B received saddle block $10 \mathrm{mg}$ of hyperbaric bupivacaine $(2 \mathrm{ml}$ of $0.5 \%)$. The blood pressure, oxygen saturation, heart rate measured and recorded subsequently. The hypotension treated by 100 mcg bolus of phenylephrine. Results: In our study there was statically significant difference $(\mathrm{p}<0.05)$ between group A which received spinal anesthesia and group $B$ which received saddle block in hemodynamic effect. In which the incidence of hypotension and vasopressor requirement more in group A. Conclusion: Under saddle block the TURP can safely performed with low risk of hypotension and less requirement of vasopressor.

Key words: spinal anesthesia, saddle block, hypotension, Phenylephrine, 


\section{introduction:}

Is the gold standard procedure for patients with bladder outlet obstruction due to benign prostatic hyperplasia (BPH), with success rate of $85-90 \%{ }^{(1)}$ TURP is mostly applied on elderly patients who have hypertension, problems with breathing, circulation system, and kidney functions, therefore, it becomes very important to keep a stable anesthesia that will minimize the hemodynamic differences in these patients. General anesthesia causes more hemodynamic differences compare to regional anesthesia ${ }^{(2)}$. Thus, regional anesthesia is highly preferable in TURP applications.

Is performed by insertion a resectoscope through the urethra and resecting prostatic tissue with an electrically powered cutting-coagulating metal loop or using laser- 22 vaporization energy. This can be accomplished with either a monopolar TURP (M-TURP) or bipolar TURP (B-TURP) technique. Laser energy for TURP has also been used for many years. With each technique, as much prostatic tissue as possible is resected, but the prostatic capsule is usually preserved. If the capsule is violated, large amounts of irrigation solution can be absorbed into the circulation via the periprostatic, retroperitoneal, or peritoneal space. Bleeding during TURP is not uncommon, but usually controllable, when large venous sinuses are opened, hemostasis becomes difficult. If bleeding becomes uncontrollable, the procedure should be terminated as quickly as possible, and a Foley catheter should be passed into the bladder and traction applied to it. The catheter's inflated balloon exerts lateral pressure on the prostatic bed and reduces bleeding. Bleeding requiring transfusion occurs in approximately $2.5 \%$ of TURP procedures. ${ }^{(3)}$

Complications of TURP have been markedly reduced after development of bipolar resectoscpoe (B-TURP) and laser resectoscope (R-TURP) in addition to 
wide spread availability of isotonic irrigation solutions ${ }^{(4)}$, these complications may include: Absorption of Irrigating Solution; Excessive Circulatory Volume, Hyponatremia, and Hypoosmolality ; Glycine Toxicity;Ammonia Toxicity; Perforation ;Transient Bacteremia and Septicemia; Hypothermia ; Bleeding and Coagulopathy.

Anesthesia Spinal anesthesia is produced by injection of a local anesthetic drug into the subarachnoid space creating a conduction blockade of the spinal nerves and resulting in a rapid, dense, and predictable state of anesthesia. Saddle anesthesia is a selective spinal anesthesia that directs a small bolus of local anesthetic toward the last four sacral spinal segments (S2-S5) and coccygeal nerve roots ${ }^{(5)}$. In saddle block anesthesia the patient remain in sitting position for at least five minutes after injection of local anesthetic, provides anesthesia in area of the perineum, buttocks, and inner thigh. An ideal "saddle block" anesthetizes the area that would touch a saddle if the patient were riding a horse. Spinal anesthesia is an ideal choice for surgeries below the level of the umbilicus. Examples include low abdominal, inguinal, genitourinary, gynecologic, rectal, and lower-extremity surgeries. Spinal anesthesia is not widely used for upper abdominal procedures because of the need for a very high level of block that may increase the risk of cardiovascular and respiratory complications. ${ }^{(6)}$ Neuraxial anesthesia is a term used to describe any form of spinal or epidural (including caudal) anesthesia. ${ }^{(6)}$ Selective involvement of sacral spinal segments (S2-S5) while saddle block results in minimum dilatation of vasculature with hypotension occurring only rarely. This beneficial activity of this block confirms its position as the safest anesthesia even at the centers with limited facilities in developing country ${ }^{(7)}$ section $2.5 \mathrm{mg}$ per $1 \mathrm{ml} 0.25 \%$ and $5 \mathrm{mg}$ per $1 \mathrm{ml} 0.5 \%$. ${ }^{(8)}$

Aim of the study: To compare hemodynamic changes between the spinal block and saddle block in transurethral resection of prostate (TURP).

patients and methods:

A randomized clinical trial study was conducted in urological operation 
theaters in Gazy Al-harrery hospital and Al-kademia teaching hospital in Baghdad, Iraq, from 1st of October 2018 to $1^{\text {st }}$ of August 2019.

Fifty patients were included in the study. From each patient Written informed consent was obtained.Inclusion criteria: Age from 50-70; Weight from 50- $90 \mathrm{Kg}$; Height from 160-180 ; ASA I - II; Scheduled for TURP, Whilst the Exclusion criteria: Patient have allergy to drugs used in study and any absolute or relative contraindication to spinal anesthesia.A 50 patients were divided in two groups, group A 25 patients received spinal block and group B 25 patients received saddle block. Information's was taken from each patient about his name, Age, past medical history, past surgical history, drug history, height, weight, general examination was done and investigation was check.

In operating room monitors for patient's ECG, HR, spo2, blood pressure was connected. 18-gauge cannula was inserted for all patient and then they received $500 \mathrm{ml}$ of crystalloid ( $0.9 \%$ normal saline) as preload. The patients was in sitting positioned and Under aseptic technique, a 25gauge sprotte needle used and $10 \mathrm{mg}$ of $0.5 \%$ hyperbaric bupivacaine was given at the level of $\mathrm{L}_{4-5}, \mathrm{~L}_{3-4}$ interspaces after the free flow confirming of the cerebrospinal fluid (CSF). Now patients were divided in two groups, group A immediately positioned in the supine position with two pillows supporting the head and shoulders. Group B were maintained in the sitting position for $10 \mathrm{~min}$. and then positioned in supine position with two pillows supporting the head and shoulders. For both groups O2 was given at rate of $3 \mathrm{lit} / \mathrm{min}$ by a nasal cannula. The BP was checked every 3 min. and baseline was recorded, a decrease of BP $25 \%$ from the baseline was treated with $100 \mu \mathrm{g}$ of phenylephrine.

Statistical analysis: The collected data was handled and analyzed by IBM@ SPSS@ (Statistical Package for the Social Sciences) Statistics Version 23. Chisquare was the test used for analyzing categorical data, with Fisher's exact modification when needed. Independent samples T-test and was used for 
numerical and normally distributed data. All analyses were done with 95\% confidence intervals $(\mathrm{CI})$. P-values less than 0.05 were considered statistically significant throughout this study.

\section{Results:}

This study enrolled 50 males undergoing $\mathrm{BPH}$ resection by endoscopy. There was statistically insignificant differences regarding the patients age, height and weight between the two study groups.

Table (1): comparison of age and weight between spinal and saddle anesthesia

\begin{tabular}{|c|c|c|c|c|c|}
\hline \multirow{2}{*}{ Variable } & \multicolumn{2}{|c|}{ Spinal } & \multicolumn{2}{c|}{ Saddle } & \multirow{2}{*}{ P-value } \\
\cline { 2 - 5 } & Mean & SD & Mean & SD & \\
\hline Age & $\begin{array}{c}65.3 \\
1\end{array}$ & 7.750 & 69.33 & 5.241 & 0.239 \\
\hline Height & $\begin{array}{c}165 . \\
31\end{array}$ & 3.988 & 167.00 & 0.894 & 0.059 \\
\hline Weight & $\begin{array}{c}75.7 \\
7\end{array}$ & 7.334 & 79.00 & 9.466 & 0.363 \\
\hline
\end{tabular}

In the current study, the systolic blood pressure (SBP) showed a statistically significant difference intraoperatively, at $6 \mathrm{~min}$, only, patients in spinal group had lower reading compared to saddle group B, in addition, as illustrated in figure (1); the SBP was more stable in saddle group.

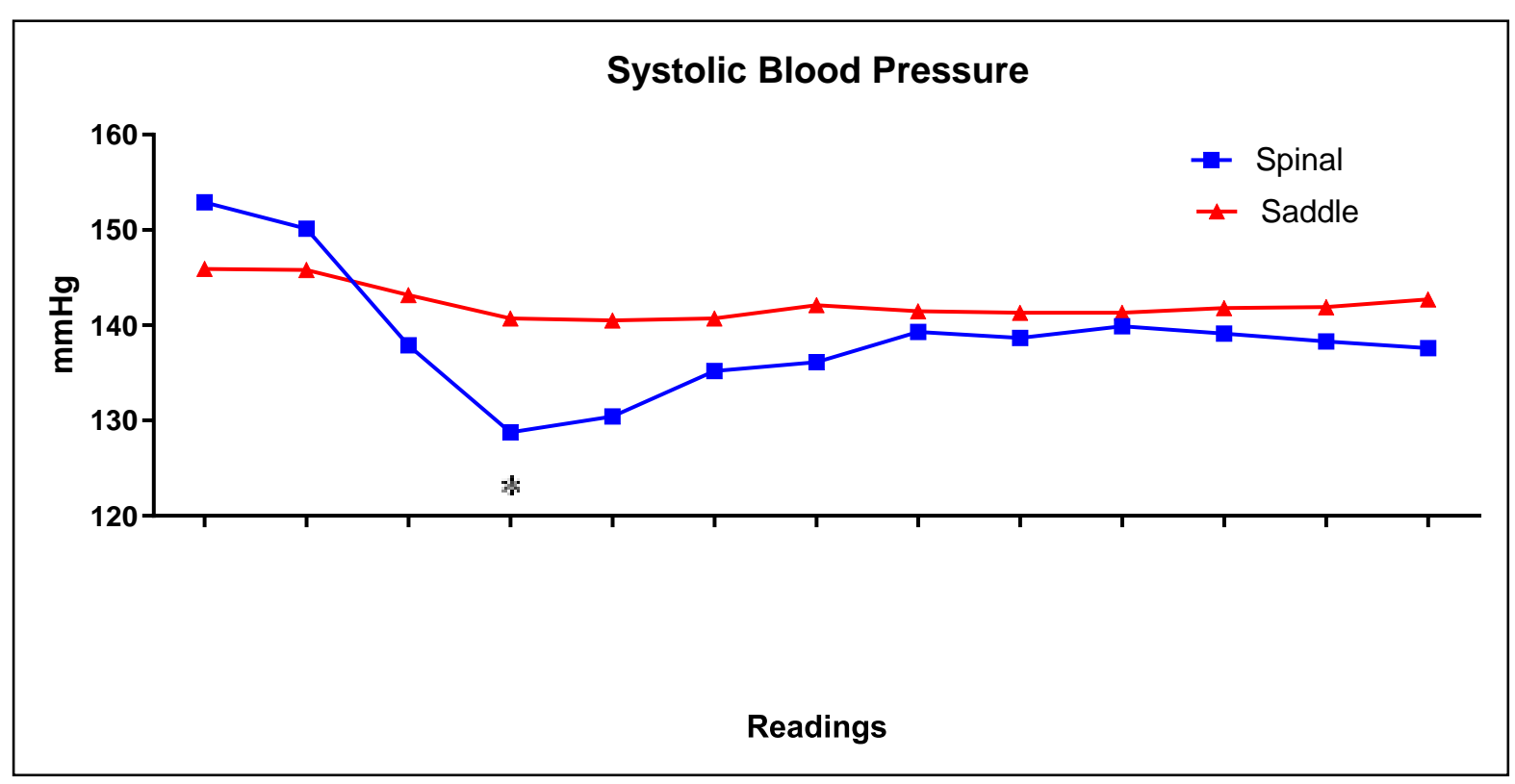




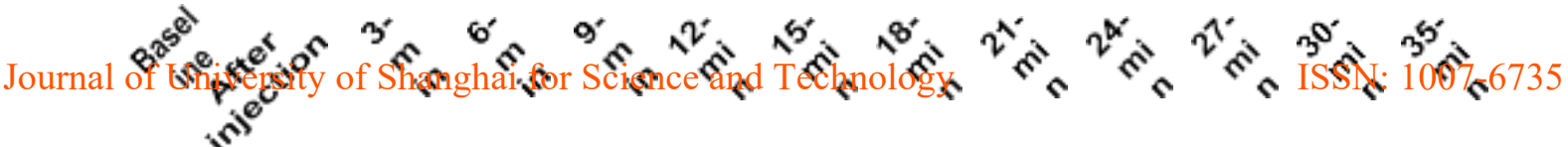

Figure (1): distribution of systolic blood pressure at different intraoperative time intervals according to study groups (theasterisk indicates statistically significant difference, $p$-value $<0.05$ ).

The diastolic blood pressure (DBP) showed statistically significant differences between the two study groups at time intervals; $3 \mathrm{~min}, 6 \mathrm{~min}$, $9 \mathrm{~min}, 12 \mathrm{~min}, 21 \mathrm{~min}, 24 \mathrm{~min}, 27 \mathrm{~min}, 30 \mathrm{~min}$ and $35 \mathrm{~min}$, as illustrated in figure (2), at all these intervals the $\mathrm{DP}+\mathrm{BP}$ was lower in spinal anesthesia group.

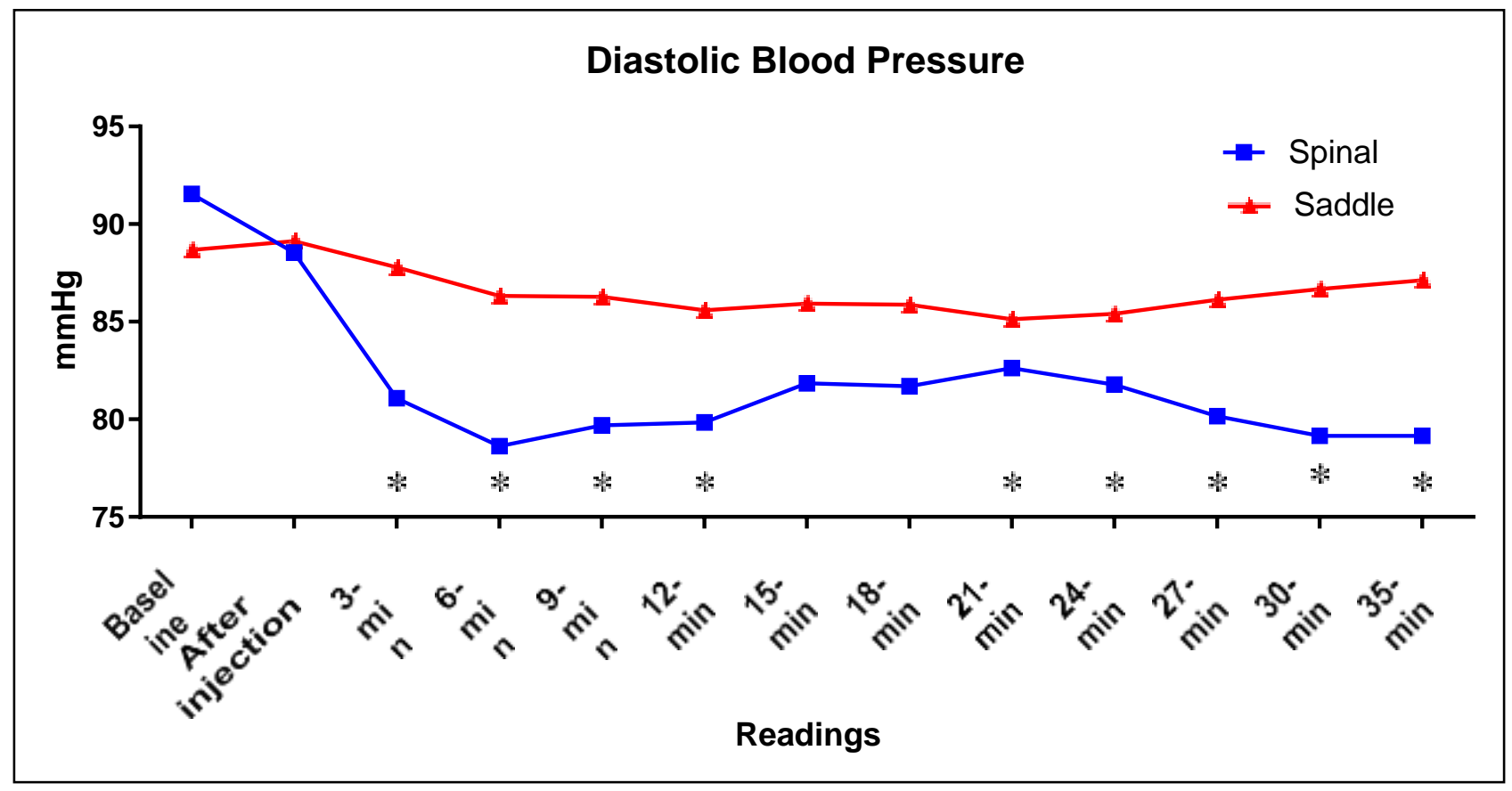

Figure (2): distribution of diastolic blood pressure at different intraoperative time intervals according to study groups (the asterisk indicates statistically significant difference, $p$-value $<0.05$ )

The mean arterial pressure (MAP) showed statistically lower levels in spinal anesthesia group at $3 \mathrm{~min}, 6 \mathrm{~min}$ and $35 \mathrm{~min}$, as illustrated in figure (3). It can be noticed that in saddle anesthesia group, the SBP, DBP and MAP were more stable in comparison to spinal anesthesia group. 


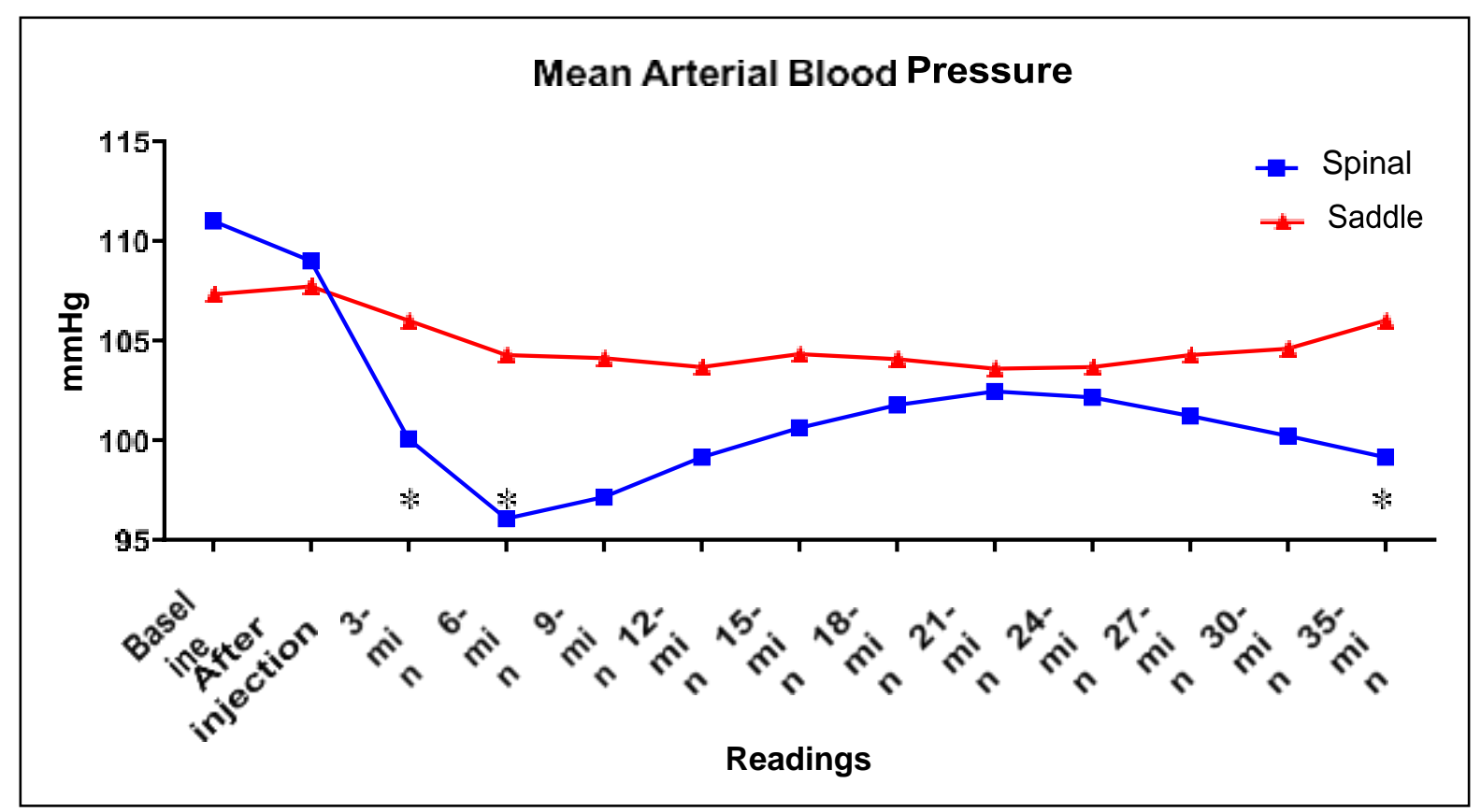

Figure (3): distribution of MAP at different intraoperative time intervals according to study groups (the asterisk indicatesstatistically significant difference, $p$-value $<0.05$ )

The pulse rate was close in both groups, with only statistically significant difference at $21 \mathrm{~min}$, as shown in figure (4).

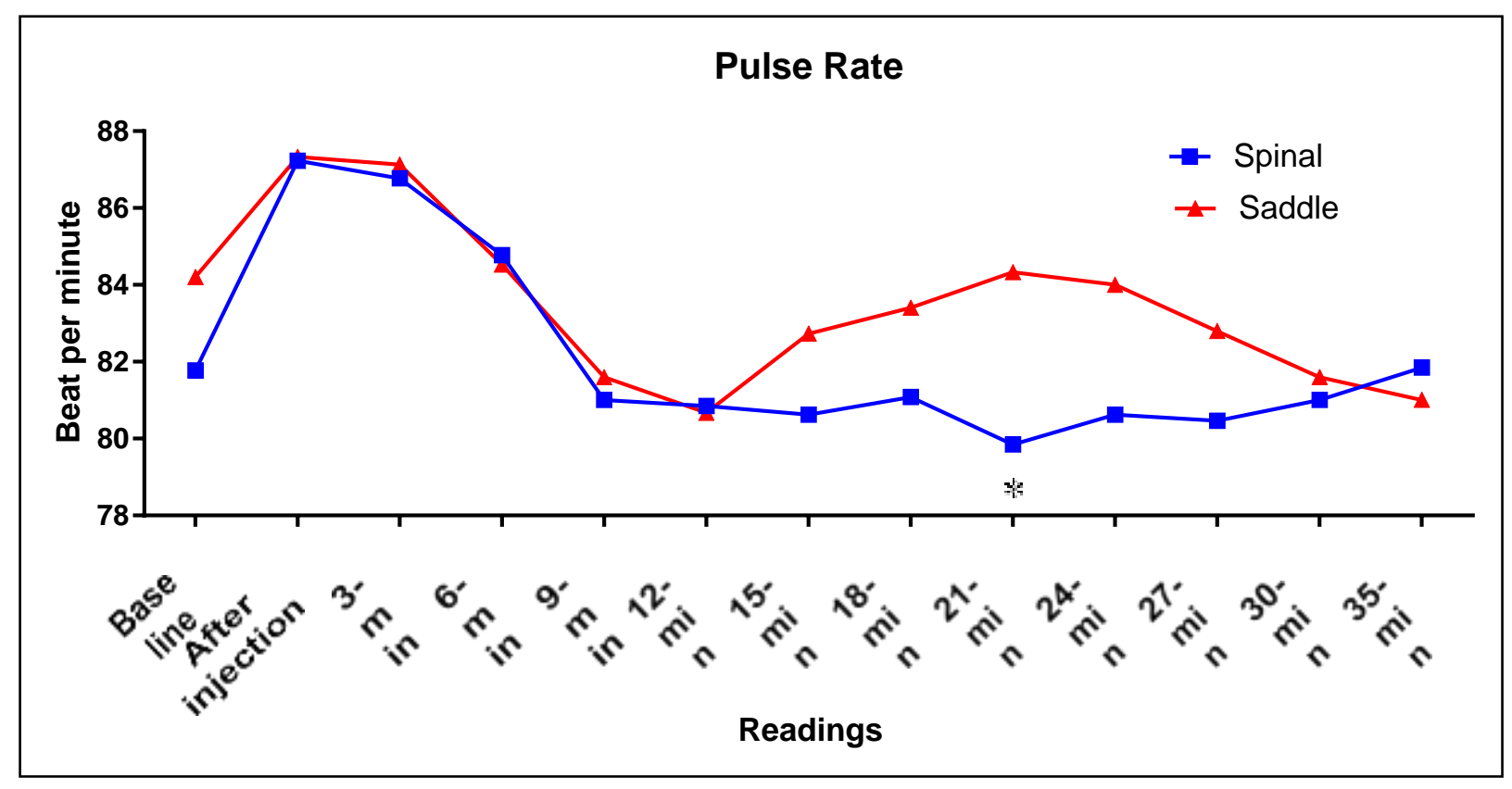

Figure (4): distribution of pulse rate at different intraoperative time intervals according to study groups (the asterisk indicates statistically significant difference, $p$-value $<0.05$ ) 
The SPO2 levels was higher than 98\% in all time intervals among both groups, and was only significantly higher in spinal anesthesia group at $3 \mathrm{~min}$ and $6 \mathrm{~min}$, while it was higher in saddle anesthesia group at 15 min, as illustrated in figure (5).

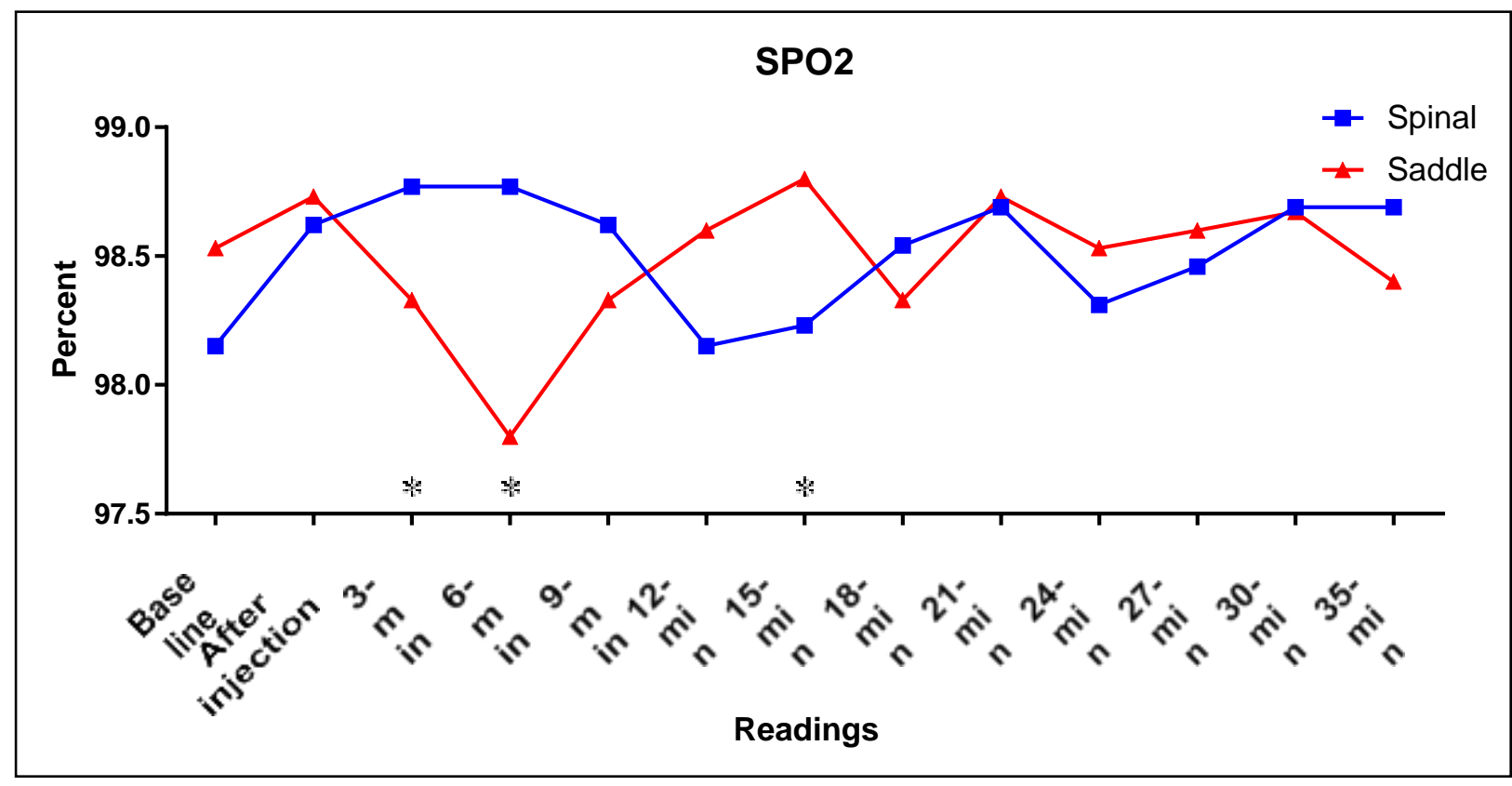

Figure (5): distribution of SPO2 at different intraoperative time intervals according to study groups (the asterisk indicates statistically significant difference, $p$-value $<0.05$ )

There was a statistically significant association between type of anesthesia and the use of phenylephrine, as there were 12 (48\%) patients who needed it in spinal anesthesia group compared to nil in saddle anesthesia group, also it was noted that most patients needed it on the sixth minute during the operation, as shown in Table (2).

Table (2): Distribution of the phenylephrine use according to study groups

\begin{tabular}{|c|c|c|c|c|}
\hline Variable & Spinal & Saddle & Total & \multirow{2}{*}{$\begin{array}{c}\text { P- } \\
\text { value }\end{array}$} \\
\cline { 2 - 4 } & No. $(\%)$ & $\begin{array}{c}\text { No. } \\
(\%)\end{array}$ & $\begin{array}{c}\text { No. } \\
(\%)\end{array}$ & \\
\hline Phenylephrine use & \multicolumn{4}{|c|}{} \\
\hline Yes & $12(48)$ & $0(0.0)$ & $12(24)$ & $<0.001$ \\
\hline No & $13(52)$ & 25 & $38(76)$ & \\
\hline
\end{tabular}




\begin{tabular}{|c|c|c|c|}
\hline & & (100) & \\
\hline Total & $25(100)$ & $\begin{array}{c}25 \\
(100)\end{array}$ & $\begin{array}{c}50 \\
(100)\end{array}$ \\
\hline
\end{tabular}

\section{Discussion:}

Regional anesthesia offers several advantages over general anesthesia for TURP. The reduction in intraoperative blood loss, decreases the hypercoagulable state in the postoperative period and maintain normal coagulation and platelet function; these benefits are believed to be due to modulation of the neuroendocrine response to tissue injury, change in the patient's mental status provides an early indication that excessive absorption of irrigating fluid has occurred, early detection of bladder perforation secondary to over distention with irrigation fluid or contact of the bladder wall with the surgeon's resectoscope. Conscious patients might experience symptoms related to perforation well before it becomes apparent to the surgeon, alerting the operating team early on. ${ }^{(7,8)}$

Spinal anesthesia and saddle block are adequate for TURP procedure in which the visceral pain sensation from the prostate and bladder neck is transmitted by afferent parasympathetic nerve fibers derived mostly from the second and third sacral nerve roots travelling with the pelvic splanchnic nerves.

Becker et al., In his study Concluded that the most important factors that affect the distribution of the local anesthesia in cerebro-spinal fluid is the physical characteristics of the local anesthetic solution and the position of the patient ${ }^{(9)}$, also various studies have already been done using $2 \mathrm{ml}$ of $0.5 \%$ hyperbaric bupivacaine for TURP (Pitkanen et al., 1984; Ozmen et al., 2003) ${ }^{(10,11)}$

In current study the group A and group B both received $10 \mathrm{mg}$ of hyperbaric bupivacaine ( $2 \mathrm{ml}$ of $0.5 \%$ ) but group A directly ling supine after injection and group B sitting for $10 \mathrm{~min}$. then ling supine. In both groups the anesthesia was provides adequate anesthesia for the patients, in group A we note that hemodynamic changes more and statistically significant $(\mathrm{p}<0.05)$ than group 
$\mathrm{B}$ and so the vasopressor requirement more in group $\mathrm{A}$.

current results supported by Bhattacharyya, Susmita et al., (Incidence of hypotension and vasopressor requirement was less $(P<0.01)$ in patients received saddle block in compare to patients received spinal anesthesia in which both groups received $10 \mathrm{mg}$ hyperbaric bupivacaine. Adequate surgical condition was achieved in both groups.)

Gujrala et al., (saddle block done with $5 \mathrm{mg}$ of hyperbaric bupivacaine $1 \mathrm{ml}$ of $0.5 \%$ with $50 \mathrm{mcg}$ fentanyl used in patients with mitral and aortic valve replacement and tricuspid annuloplasty for TURP without any deleterious cardiovascular effect.) ${ }^{(12)}$

Also, some of the studies that support our study that noted that HR values decreases after the spinal anesthesia ${ }^{(13,14)}$.

Conclusion: The hemodynamic changes and vasopressor requirement are less with saddle block, as well as Saddle block provide s adequate anesthesia for TURP procedure.

\section{References:}

1. Mebust WK, Holtgreive HL, Cockett AT, Peters PC: Transurethral prostatectomy - immediate and postoperative complications: a cooperative study of 13 participating institutions evaluating 3,885 patients, J Urol 141:243-247, 2001.

2. Dobson PM, Caldicott LD, Gerrish SP, et al., Changes in haemodynamic variables during transurethral resection of the prostate: comparison of general and spinal anaesthesia. Br J Anaesth 2006 Mar; 72(3): 267-271.

3. Hatch PD: Surgical and anaesthetic considerations in transurethral resection of the prostate, Anaesth Intensive Care 15:203-211,1987

4. Malhotra, V., Sudheendra, V., O'Hara, J. et al., Anesthesia and the renal 
and genitourinary systems. In: Miller RD. editor. Miller's Anesthesia. 8th ed. Philadelphia: Churchill Livingstone; 2015. p. 2217- 43.

5. Carron M, Innocente F, Veronese S, et al., Subarachnoid anesthesia for loco-regional antiblastic perfusion with circulatory block (stop-flow perfusion). Minerva Anestesiol 2006; 72:37-45.

6. Ivan TV, Assia V. Spinal Anesthesia. In: Essential Clinical Anesthesia, 1st ed. CAMBRIDGE; 2011. p. 340

7. Rowling son JC, Terence MM: Chronic pain, Anesthesiology, 5th edition, Edited by Miller RD. Philadelphia, Churchill Livingstone, 2000, pp 235179

8. BNF 74 September 2017- March 2018.

9. Becker N, Calleserk T, Thage B, Bertelsel F, Christianses C. Level of injection in spinal anaesthesia: Effect on sensory anesthetic level. Reg Anesth 1993; 18: 44-46.

10.Pitkanen, M., Haapaniemi, L., Tuominen, M., et al., 2014. Influence of age on spinal anaesthesia with isobaric $0.5 \%$ bupivacaine. $\mathrm{Br} \mathrm{J}$ Anesth., $56: 279-84.36$.

11.Ozmen, S., Kosar, A., Soyupek, S et al., 2003. The selection of regional anesthesia in TURP operation. Int Urol Nephrol., 35:507-12.

12.Gujrala, I., Vaddi, S., Devraj, R. 2001. Anaesthetic management of transurethral resection of prostate in a patient with aortic and mitral valve replacement. Indian J Anaesth., 55:435-37.

13. Toft P, Bruun-Mogensen CHR, Kristensen J, et al., A comparison of glucose-free 2\% lidocaine and hyperbaric 5\% lidocaine for spinal anaesthesia. Acta Anaesth Scand 2010; 34(2): 109-113. 40. 
14.Baraka AS, Taha SK, Ghabach MB. et al., Hypertonic saline prehydration in patients undergoing transurethral resection of the prostate under spinal anesthesia. Br J Anaesth 2004; 72: 227-228. 